OPEN ACCESS

Edited by:

Marta Montserrat,

Institute of Subtropical and

Mediterranean Horticulture La

Mayora, Spain

Reviewed by:

Michael J. Stout,

Louisiana State University,

United States

Odair Aparecido Fernandes,

São Paulo State University, Brazil

Madelaine Venzon,

Agronomical Research Institute of

Minas Gerais, Brazil

*Correspondence:

Nozomi Kawarazuka

n.kawarazuka@cgiar.org

Specialty section:

This article was submitted to

Pest Management,

a section of the journal

Frontiers in Agronomy

Received: 23 April 2020 Accepted: 02 June 2020

Published: 03 July 2020

Citation:

Kawarazuka N, Damtew E, Mayanja S, Okonya JS, Rietveld A, Slavchevska V

and Teeken B (2020) A Gender

Perspective on Pest and Disease

Management From the Cases of

Roots, Tubers and Bananas in Asia

and Sub-Saharan Africa.

Front. Agron. 2:7.

doi: 10.3389/fagro.2020.00007

\section{A Gender Perspective on Pest and Disease Management From the Cases of Roots, Tubers and Bananas in Asia and Sub-Saharan Africa}

\author{
Nozomi Kawarazuka ${ }^{1 *}$, Elias Damtew ${ }^{2}$, Sarah Mayanja ${ }^{3}$, Joshua Sikhu Okonya ${ }^{4}$, \\ Anne Rietveld ${ }^{5}$, Vanya Slavchevska ${ }^{6}$ and Béla Teeken ${ }^{7}$ \\ ${ }^{1}$ Social and Nutrition Sciences Division, International Potato Center, Hanoi, Vietnam, ${ }^{2}$ Knowledge, Technology and \\ Innovation Group, Wageningen University, Wageningen, Netherlands, ${ }^{3}$ Social and Nutrition Sciences Division, International \\ Potato Center, Kampala, Uganda, ${ }^{4}$ Crop and System Sciences Division, International Potato Center, Kampala, Uganda, \\ ${ }^{5}$ Alliance of Bioversity International and CIAT, The Hague, Netherlands, ${ }^{6}$ Crops for Nutrition and Health, Alliance of Bioversity \\ International and CIAT, Cali, Colombia, ${ }^{7}$ Cassava Breeding Unit \& Social Science Group, International Institute of Tropical \\ Agriculture, Ibadan, Nigeria
}

Considering gender in research on pests and diseases is increasingly important as it facilitates development of more efficient approaches to increasing the adoption of crop protection technologies and practices by women and men farmers according to their roles, knowledge, and capacities. However, this task is often assigned to social scientists in isolation from agronomists. Meanwhile, agronomists often struggle to understand how taking a gender perspective could enrich their research. Drawing on a number of different cases from both published and unpublished field research in Asia and sub-Saharan Africa, this perspective article illustrates how a gender perspective can broaden the aspects of agronomy research and thereby contribute to improving crop production and scaling up of existing technologies and practices. Its targeted audience are agronomists and development practitioners, in particular, young researchers who are central to transdisciplinary agricultural research in the future.

Keywords: gender, pest and disease control, extension work, roots and tubers, banana

\section{INTRODUCTION}

Women and men farmers often play different roles in agricultural production, and they possess different levels of knowledge about, and involvement in, pest and disease management practices. Despite these gender differences, pest and disease management research and training often targets "farmers," neglecting the specific needs of women and men as well as the power relationships within households and communities. Such oversight is particularly important since providing gender-appropriate support to women and men farmers helps to increase the adoption of appropriate crop protection technologies and practices, reduce farmers' exposure to pesticides, and improve environmental quality (Christie et al., 2015). While a gender perspective is increasingly recognized in the field of agricultural extension and training (Lambrecht et al., 2016; Mudege et al., 2016; Lamontagne-Godwin et al., 2017), it is often insufficiently considered by agronomists and crop protection experts, who are focused on bio-technical solutions and pay little attention to social-economic factors and power relations among farmers in the field and off the field. 
This article seeks to provide specific insights into how a gender perspective can contribute to enhancing agronomy research and extension practices. We specifically focus on roots, tubers and bananas (RTB), which are important crops for poor people in the global south. The control of pests and diseases has increasingly become important for these crops, not only to improve productivity in the face of climate change but also to improve the quality of crops readied for the commercial market with increased attention and demands for safe produce. Several control measures are available to address these concerns, such as: pesticide application; cultural, biological, and mechanical control methods; the use of disease-resistant varieties of crops; botanicals; clean seed; crop rotation; mulching; intercropping; and timely planting. To facilitate the adoption of those control methods, it is critical to explore farmers' perceptions, experiences and practices from a gender perspective. To provide an in-thefield perspective on gender as an entry point, this article presents six cases from our recent field studies in Asia and sub-Saharan Africa. It then discusses the significance of integrating the gender perspective in transdisciplinary agronomy research.

\section{CASES FROM THE FIELD}

Below we present six examples of how gender roles influence pest and disease management (cases 1 and 2); how differently women and men perceive and control pests and diseases (case 3 ); why some farmers do not follow the best measures suggested by scientists (cases 4 and 5); and what considerations are needed when developing and disseminating disease resistant varieties (case 6).

\section{Understanding Gender Roles Is Critical for the Implementation of Pest and Disease Management}

In Uganda, Rwanda, and Burundi, there is frequent use of pesticides in potato farming systems to control major insect pests such as cutworms, psyllids, lygus bugs, leafminers, aphids, and armyworms (Okonya and Kroschel, 2016; Okonya et al., 2019a). A recent study (Okonya et al., 2019b) shows that men apply the chemicals in the field usually without any personal protective equipment, while women fetch the water to be used for mixing the pesticides, and also wash the clothes worn during the pesticide application. However, women are often not invited to participate in training about the safe use and handling of pesticides organized by extension workers, who are often men. As a result, women are exposed to the negative effects of pesticides because they frequently do not know about the toxicity levels of the different chemicals being used and their impacts on health as well as the environment. If women were more aware of the hazards, they could influence their husbands to adopt safe practices around pesticide application (see for example, Lambrecht et al., 2016). Therefore, both women and men should be given training about the safe use and handling of pesticides and other agro-chemicals so that both can avoid pesticide poisoning and contribute to effective crop management.

\section{Understanding Gender Roles and Relationships Helps Control Banana Xantomonas Wilt in the East-African Highlands}

Banana Xanthomonas Wilt (BXW) poses a major threat to banana production in the East-African highlands. The Single Diseased Stem Removal (SDSR) control package is highly effective in controlling the disease and less labor intensive compared to other management practices, as farmers do not need to uproot complete banana mats. Instead, they simply cut stems that show any symptoms of BXW at soil level (McCampbell et al., 2018). In this region, banana production is primarily controlled by men, and extension services have often targeted men. In the RTB Scaling fund project; broadening the scaling of BXW management in East and Central Africa, we found that such targeting proved to be problematic for many banana producing households since many men have migrated to mines and urban centers while women have remained behind and manage banana production. This means they often manage all tasks in a banana plantation in the absence of their husbands, including managing disease, although they do not own the plots. It also means that they may harvest bananas for consumption or sale. In the training in this project in the DRC, both men and women were therefore targeted.

A study in Burundi (Iradukunda et al., 2019) provides another example. In many households in Burundi, bananas are intercropped with food crops, such as climbing beans which uses the banana stem as climbing support. The beans are commonly managed by women to meet food security needs. SDSR procedures to remove infected stems during the bean growth season can negatively influence bean production because bean plants may be damaged. Nevertheless, reducing BXW remains a priority because banana yield losses also impact household nutrition and income. Since household conflicts over crop and tree management can undermine efforts to improve livelihoods, strategic management of crops and trees will require improved intra-household decision-making and practical joint efforts to support the knowledge of both women and men (Rietveld and Farnworth, 2018). Such a gender-responsive approach can be copied in neighboring countries in the region where similar gender dynamics exist.

\section{Men and Women Use Different Languages and Have Different Views on Pests}

Women and men from the same community perceive pests in very different ways. This was found in our recent fieldwork in Ethiopia and Ghana in the case of sweet potato. In East Badaawacho Woreda Hadiya zone, Southern Ethiopia, women call one particular pest (millipedes, Omopyge sudanica) "Daafura", while men call the same pest "Bini". Men further noted that the pest spreads in dry seasons and likes lodging in fertile soil. Men and women also adopted different control methods which are in line with their gender roles: men practice early planting to prevent infestation as they are in charge of plowing, while women spend their time in the field 
hunting the pests and killing them as they are responsible for routine management.

In field work carried out in a community in Gushegu district in northern Ghana, we found that women consider an insect (adult sweet potato weevils, Cylas spp) called "Zunzuli" to be the most serious pest for sweet potato. After harvesting, they carefully check for the presence of adult weevils in all roots, cutting off infested parts before storing them. They think that treating vines with insecticides could be a solution, since the eggs of the pest may be hidden in the vines. In contrast, men consider maggots (the larval stage of sweet potato weevils) the most serious pest, not the adult stage of the sweet potato weevil mentioned by the women. Consequently, men harvest early to prevent weevil infestation of the sweet potato roots. These cases show that understanding women's and men's knowledge of pests and their control methods based on years of practical experience. Is important in addressing their concerns and providing appropriate practices in response to their genderrelated understandings and practices.

\section{Providing More Knowledge or Technical Skills to Women Is Not Enough}

In Ethiopia, potato late blight represents a serious problem for farmers in almost all major potato-growing areas (Woldegiorgis et al., 2008; Tsedaley, 2014). To collectively address this issue at a community level, a social learning exercise was conducted as part of a broader joint research project of Wageningen University and CGIAR Research Program on RTB. A study conducted in this project shows an important gender aspect (Damtew et al., 2020). The farmers' group initiated a disease monitoring system for early diagnosis of late blight and a community by-law to ensure implementation of various management practices. The group identified that it is mainly women farmers who fail to regularly implement agreed practices, such as joint field scouting for disease diagnosis. Moreover, some of the women farmers were not able to spray their fields as per the collective agreement due to lack of financial resources to purchase fungicides at the time of late blight incidence. This led to sanctions and monetary fines that mainly affected women farmers, who already had less access to financial resources than men. Understanding the socioinstitutional problems of late blight management has enabled the group to address some of the gender-based constraints that women potato farmers face. The women farmers' inability to spray their fields made the farmers' monitoring committee realizes that putting a system of sanctions in place would not guarantee the full compliance of all farmers, especially the women. After a deliberation process, they decided to financially support the female farmers, highlighting the risk of disease spread if those female farmers are unable to spray. One key lesson from this research approach is that addressing the gaps in women farmers' knowledge is by no means sufficient to deal with the problem of potato disease management: there has to be a corresponding learning process on how to deal with existing and emerging gendered socio-institutional constraints.

\section{Gender Matters in Controlling the Spread of Cassava Diseases in Mainland Southeast Asia}

In Mainland Southeast Asia, cassava is grown predominantly as an industrial crop for the global starch, livestock feed, and biofuel markets. It is an important cash crop for the poor. In general, both women and men work together in cassava production with some tasks, such as harvesting, divided (e.g., during harvest men often pull out the roots, while women cut the roots from the stem). Cassava mealybug, cassava witches' broom disease and cassava mosaic disease are three major pests and diseases for farmers in this region (Graziosi et al., 2016; Minato et al., 2019). Mealybug, which once caused widespread crop losses, has largely become controllable by using biological controls. However, cassava mosaic disease is very new to the region and cassava witches' broom disease remains poorly understood to the extent that the vectors remain unknown. Access to clean stems and the increased awareness of diseases can slow the spread (Delaquis et al., 2018).

A recent study, applying multiple regression analyses to survey data from Cambodia and Lao $\mathrm{PDR}^{1}$, revealed intriguing results about women and men farmers' interest in purchasing clean planting material. When the incidence of disease is rather low, as in Laos at the time of the survey, all farmers reported low interest in purchasing clean planting material with no significant gender differences in those indicators. When the incidence of pest and disease is high, as in Cambodia, farmers' interest and willingness to pay for clean planting material is also high. However, women household heads, most of whom were widowed, separated or living in households where the spouse was away, were significantly less interested in purchasing clean planting material than men or women in male-headed households, controlling for other characteristics including income. The gap was nearly 30 percentage points. Several factors may explain this, including women's lower knowledge and access to information about controlling certain diseases through the use of clean planting material, and lower levels of access to agricultural training and resources than men. The results indicate that specific support is needed for femaleheaded households to understand their attitudes toward and constraints concerning the use of clean planting material. This is an area that deserves more attention in order to reduce the risk of spreading diseases within and across communities.

\section{Women's Trait Preferences Should Be Considered When Replacing Existing Varieties With Disease Resistant Ones}

In Nigeria, cassava is an important crop for home consumption and selling. There are a variety of cassava fermented food products such as gari, eba and fufu/akpu, that are mainly processed by women. Currently, cassava disease pressure is relatively low. However, with the gradual movement of Cassava

\footnotetext{
${ }^{1}$ The survey samples consisted of 311 cassava-producing households in two provinces in Cambodia (Kratie and Stung Treng provinces) and 360 cassavaproducing households in two provinces in Lao PDR (Bolikhamsay and Xayabouly).
} 
Brown Streak Disease from East to West Africa (Patil et al., 2015), it is expected that this destructive disease will cause major losses in West Africa as it directly affects root quality. As breeders and other stakeholders work to prevent such diseases by replacing existing varieties with resistant ones, gender must be considered as an important factor influencing future use and adoption of these varieties. Research carried out by IITA within the Cornell University led Nextgen cassava project shows that women attribute more importance to cassava variety traits related to processing and food product quality than men because of their gendered roles as cassava processors (Teeken et al., 2018). Although both men and women farmers sell fresh roots, these roots are mainly sold to women processors for value addition or processed directly by women farmers. Since fresh cassava prices are relatively low in Nigeria, processing cassava into storable products adds significant value, especially for women processors and their households. Therefore, breeding programs must directly work together with women end-users, the national variety release community and extension services to make sure that new disease resistant varieties that are released and promoted, accommodate women's cassava processing and food quality preferences.

\section{DISCUSSION}

The above cases from the field have shown that adopting a gender perspective while conducting agronomic research and extension work has a great potential to provide more efficient approaches to managing pests and diseases at the field level. A gender perspective promotes new ideas and approaches to agronomy research and crop protection. First, it allows researchers to move beyond exploring the issues of pests and diseases in a single crop and single scientific discipline toward exploring crop systems as women and men farmers' strategies for controlling pests and diseases are closely associated with their interests and priorities in other crops (case 3). Second, it also enables researchers to explore a broader value-chain process of the targeted crop rather than focusing on the particular stage of production where pests and diseases take place. For example, it is critical to understand seed systems and gendered constraints therein in the case of controlling cassava diseases in Southeast Asia (case 5), while

\section{REFERENCES}

Christie, M. E., Van Houweling, E., and Zseleczky, L. (2015). Mapping gendered pest management knowledge, practices, and pesticide exposure pathways in Ghana and Mali. Agr. Hum. Values. 32, 761-775. doi: 10.1007/s10460-015-9590-2

Damtew, E., van Mierlo, B., Lie, R., Struik, P., Leeuwis, C., Lemaga, B., et al. (2020). Governing a collective bad: social learning in the management of crop diseases. Syst. Pract. Act. Res. 33, 111-134. doi: 10.1007/s11213-019-09518-4

Delaquis, E., Andersen, K. F., Minato, N., Cu, T. T. L., Karssenberg, M. E., Sok, S., et al. (2018). Raising the stakes: cassava seed networks at multiple scales in Cambodia and Vietnam. Front. Sustain. Food Syst. 2:73. doi: 10.3389 /fsufs.2018.00073

Graziosi, I., Minato, N., Alvarez, E., Ngo, D. T., Hoat, T. X., Aye, T. M., et al. (2016). Emerging pests and diseases of South-east Asian cassava: a comprehensive considering post-harvest market demands can be a first entry point in replacing local varieties with disease resistant ones (case 6). Third, research from a gender perspective necessarily explores problems and solutions from the viewpoint of women and men farmers instead of "scientists." Understanding how women and men perceive the issues and what women and men do and do not is a first step in providing appropriate solutions (cases 1 and 2) and a critical analysis of gendered power dynamics is essential to find appropriate solutions (cases 4). To achieve these, gender-responsive participatory research and participatory approaches in extension work are essential. It is also important for agricultural organizations to provide enabling conditions for researchers to adopt a gender perspective, such as facilitating transdisciplinary research and increasing female researchers and female extension workers.

\section{DATA AVAILABILITY STATEMENT}

The original contributions presented in the study are included in the article/supplementary material, further inquiries can be directed to the corresponding author/s.

\section{AUTHOR CONTRIBUTIONS}

The first author led the writing of this article. The following co-authors provided cases and technical guidance (alphabetical order by family name).

\section{FUNDING}

This research was undertaken as part of and funded by the CGIAR Research Program on Roots, Tubers and Bananas (RTB), and supported by CGIAR Trust Fund contributors (https://www. cgiar.org/funders/).

\section{ACKNOWLEDGMENTS}

We thank Jan Kreuze, James Legg, Netsayi Mudege, Steven Michael Cole, Jonathan Newby, and Renee Bullock for their useful comments on the earlier draft. We are grateful to three reviewers for their useful comments and suggestions.

evaluation of geographic priorities, management options and research needs. Pest Manag. Sci. 72, 1071-1089. doi: 10.1002/ps.4250

Iradukunda, F., Bullock, R., Rietveld, A., and van Schagen, B. (2019). Understanding gender roles and practices in the household and on the farm: Implications for banana disease management innovation processes in Burundi. Outlook. Agr. 48, 37-47. doi: 10.1177/0030727019831704

Lambrecht, I., Vanlauwe, B., and Maertens, M. (2016). Agricultural extension in Eastern Democratic Republic of Congo: does gender matter? Eur. Rev. Agric. Econ. 43, 841-874. doi: 10.1093/erae/jbv039

Lamontagne-Godwin, J., Williams, F., Bandara, W. M. P. T., and Appiah-Kubi, Z. (2017). Quality of extension advice: A gendered case study from Ghana and Sri Lanka. J. Agr. Educ. Ext. 23, 7-22. doi: 10.1080/1389224X.2016.123 0069

McCampbell, M., Schut, M., Van den Bergh, I., van Schagen, B., Vanlauwe, B., Blomme, G., et al. (2018). Xanthomonas Wilt of Banana (BXW) in Central 
Africa: opportunities, challenges, and pathways for citizen science and ICTbased control and prevention strategies. NJAS-Wagen. J. Life. Sci. 86, 89-100. doi: 10.1016/j.njas.2018.03.002

Minato, N., Sok, S., Chen, S., Delaquis, E., Phirun, I., Le, V. X., et al. (2019). Surveillance for Sri Lankan cassava mosaic virus (SLCMV) in Cambodia and Vietnam one year after its initial detection in a single plantation in 2015. PLoS ONE. 14:e0212780. doi: 10.1371/journal.pone.0212780

Mudege, N. N., Chevo, T., Nyekanyeka, T., Kapalasa, E., and Demo, P. (2016). Gender norms and access to extension services and training among potato farmers in Dedza and Ntcheu in Malawi. J. Agr. Educ. Ext. 22, 291-305. doi: 10.1080/1389224X.2015.1038282

Okonya, J. S., and Kroschel, J. (2016). Farmers' knowledge and perceptions of potato pests and their management in Uganda. J. Agri. Rural. Dev. Trop. $117,87-97$.

Okonya, J. S., Mudege, N. N., Rietveld, A. M., Nduwayezu, A., Kantungeko, D., Hakizimana, B. M., et al. (2019b). The role of women in production and management of RTB crops in rwanda and burundi: do men decide, and women work? Sustainability 11:4304. doi: 10.3390/su11164304

Okonya, J. S., Petsakos, A., Suarez, V., Nduwayezu, A., Kantungeko, D., Blomme, G., et al. (2019a). Pesticide use practices in root, tuber, and banana crops by smallholder farmers in Rwanda and Burundi. Int. J. Environ. Res. Public Health. 16:400. doi: 10.3390/ijerph160 30400

Patil, B. L., Legg, J. P., Kanju, E., and Fauquet, C. M. (2015). Cassava brown streak disease: a threat to food security in Africa. J. Gen. Virol. 96, 956-968. doi: 10.1099/jgv.0.000014
Rietveld, A., and Farnworth, C. R. (2018). Towards Gender-Responsive Banana Research for Development in the East-African Highlands. GENNOVATE Resources for Scientists and Research Teams. Mexico: CIMMYT. 6.

Teeken, B. O., Olaosebikan, I., Haleegoah, E., Oladejo, T., Madu, A., Bello, E., et al. (2018). Cassava trait preferences of men and women farmers in Nigeria: implications for breeding. Econ. Bot. 72, 263-277. doi: 10.1007/s12231-018-9421-7

Tsedaley, B. (2014). Late blight of potato (Phytophthora infestans) biology, economic importance and its management approaches. J. Bio. Agri. Healt. Care. $25,215-226$.

Woldegiorgis, G., Gebre, E., and Lemaga, B. (eds.). (2008). "Overview of trends in root and tuber crops research in Ethiopia, in Root and Tuber Crops: The Untapped Resources (Addis Ababa: Ethiopian Institute of Agricultural Research (EIAR)).

Conflict of Interest: The authors declare that the research was conducted in the absence of any commercial or financial relationships that could be construed as a potential conflict of interest.

Copyright (๑) 2020 Kawarazuka, Damtew, Mayanja, Okonya, Rietveld, Slavchevska and Teeken. This is an open-access article distributed under the terms of the Creative Commons Attribution License (CC BY). The use, distribution or reproduction in other forums is permitted, provided the original author(s) and the copyright owner(s) are credited and that the original publication in this journal is cited, in accordance with accepted academic practice. No use, distribution or reproduction is permitted which does not comply with these terms. 